\section{NALLD OFFICERS}

(as of October 1981)

President

Vice President/

President Elect

Executive Secretary

Recording Secretary

Treasurer and Advertising Manager

Director of

NALLD Publications Center

NALLD Journal

Editor-in-Chief
Joseph H. Sheehan, Director

Language Laboratory

Language and Culture Center

Department of English

University of Houston

Houston, Texas 77004

(713) $749-2716$

Victor H. Aulestia, Director

Department of Instructional Media

Resources

University of Maryland-Baltimore County

Catonsville, Maryland 21228

(301) $455-3208$

Samuel E. Burggraaf

David O. McKay Institute

W 162 Stadium

Brigham Young University

Provo, Utah 84602

(801) $378-7084$

Jackie Tanner, Director

Language Learning Technology

School of Languages and Linguistics

Georgetown University

Washington, D.C. 20057

(202) 625-4235

Leslie F. Bailey, Director

Language Laboratory

48B Kresge Centennial Hall

Northwestern University

1859 Sheridan Road

Evanston, Illinois 60201

(312) 492-3360

Charles Richardson, Director

Language Laboratories

26A Ellis Hall

Ohio University

Athens, Ohio 45701

(614) 594-5795

Dale V. Lally Jr., Director

A\&S Learning Laboratory, Bingham

Humanities 16

University of Louisville

Louisville, Kentucky 40292

(502) 588-5924 